\title{
Gliadin genotypes worldwide for spring wheats (Triticum aestivum L.) 2. Strong differentiation of polymorphism between countries and regions of origin
}

\author{
E. Metakovsky ${ }^{\mathrm{a}}$, V.A. Melnik ${ }^{\mathrm{b}}$, L. Pascual ${ }^{\mathrm{a}}$, C.W. Wrigley ${ }^{\mathrm{c}, *}$ \\ ${ }^{a}$ Unit of Genetics, Department of Biotechnology - Plant Biology, Universidad Politecnica de Madrid, Madrid, 28040, Spain \\ ${ }^{\mathrm{b}}$ Vavilov Institute of General Genetics, Russian Academy of Sciences, 119991, Moscow, Russia \\ ${ }^{\mathrm{c}}$ QAAFI, University of Queensland, Brisbane, QLD 4072, Australia
}

A R T I C L E I N F O

\section{Keywords:}

Gliadin alleles

Wheat-gene geography

Genetic diversity

History

\begin{abstract}
A B S T R A C T
Genotypes of 290 cultivars from ten countries (four continents) of spring wheat Triticum aestivum, were analyzed through the identification of alleles at the gliadin-encoding (Gli) loci. The group of cultivars bred in one country during the 20th century might be characterized by its level of genetic diversity $(H)$ and a specific set of alleles. Strong differences between genotypes of cultivars bred in different countries were confirmed by cluster analysis of genetic distances. Genotypes of cultivars bred in regions of the same country might differ, but they always composed a single cluster and strongly differed from genotypes from other countries or regions. Therefore, world polymorphism of spring wheat germplasm of the 20th century is highly structured and differentiated between countries and their regions. This differentiation seems to be mainly a result of natural selection acting in different ways in different eco-climatic conditions of breeding and propagation. At a regional scale, statistically significant temporal changes in frequency of some gliadin alleles and a tendency to temporal decrease of overall genetic diversity were discovered in cultivars bred in each of seven regions studied in Australia, Canada and the former USSR. In regions of Canada (provinces of Manitoba and Ontario) and of the former USSR (Saratov), a statistically significant decay of the genetic diversity of cultivars bred during the 20th century was discovered. However, the influence of breeders' selection for end-use wheat quality on the wheat genetic diversity was the least, if any.
\end{abstract}

\section{Introduction}

There has been a discussion (reviewed in Porceddu et al., 1988; Brown and Hodgkin, 2015; Thormann and Engels, 2015) about possible decreases in the level of genetic diversity (genetic erosion) of wheat germplasm during the 20th century. An important factor which might influence negatively on wheat genetic diversity was the selection, in different countries, for a similar set of wheat characters, for example, for improved end-use (dough) quality. Indeed, the frequency of some particular quality-related alleles of storage proteins (glutenins and gliadins) was found to increase with time in wheat germplasm studied (Branlard et al., 2003; Ribeiro et al., 2011; Metakovsky et al., 2019). At the same time, it was noticed that genotypes of cultivars bred in one country were simiar, but they might differ strongly between countries (Metakovsky et al., 2018).

The wheat seed storage protein, gliadin, has immense and wellstudied polymorphism based on multiple allelism at each of the six main Gli loci. Therefore, gliadin alleles provide a set of suitable genetic markers for the identification and comparison of wheat genotypes (reviewed in Metakovsky, 2015; Metakovsky et al., 2018), and their use for analysis of world-wide wheat genetic diversity has been fully justified.

There are various interpretations of the term "erosion" and different approaches for its evaluation (discussed in Fu and Somers, 2009; Brown and Hodgkin, 2015). In this work, we characterized the genetic diversity in a given group of cultivars, first, by the level of genetic diversity index $(H)$, second, by a set of alleles occurring frequently in this group, and, third, by a number of different alleles detected in the group.

The detailed spatial and temporal analysis of French wheat germplasm indicated that several determinants of genetic diversity could act at a finer spatial scale than nationwide (Perronner et al., 2017). Therefore, we studied, using gliadin alleles, the diversity of spring wheat at the regional level (across areas of a country) and with respect to time scale throughout the 20th century.

\footnotetext{
* Corresponding author. QAAFI, University of Queensland, Brisbane, QLD 4072, Australia.

E-mail address: C.Wrigley1@uq.edu.au (C.W. Wrigley).
} 


\section{Materials and methods}

\subsection{Grain materials}

In total, grain samples of 290 cultivars and lines of spring wheat ( $T$. aestivum L.) were obtained from genetic and/or breeding laboratories from the countries of origin of cultivars. In addition, nine Spanish landraces were included in the analysis (Supplementary material, List S1).

The internet site wheatpedigree. net was used to establish the pedigree of a cultivar, its phenotype (botanical variety), winter/spring habit, year of release, and region (province) of a country where it was bred.

\subsection{Methods}

Gli alleles in all genotypes studied were identified earlier (List S1 in Metakovsky et al., 2018, and in Metakovsky et al., 2019). It is known that the identification of some gliadin alleles at the Gli-B2 locus in some wheat genotypes is difficult (Metakovsky et al., 2018). In this work, alleles at the Gli-B2 locus were not perfectly identified in several cultivars bred in Nordic countries. Therefore, it was not possible to use these for futher calculations neither ambiguously identified alleles nor selectively to use only those cultivars bred in Nordic countries in which alleles at the Gli-B2 were well-identified (Tables 1 and 2). For Nordic countries, all calculations were performed for five main Gli loci (without Gli-B2).

An allele occurring with the frequency of $>40 \%$ at a given Gli locus in a given group of cultivars was assumed to be the most frequent gliadin allele (MFGA) and is shown in Tables 1-3.

The genetic diversity index $(H)$ at a Gli locus in a group of cultivars was computed as $H=1-\Sigma p^{2}$, where $p$ is a frequency of an allele at this locus (Nei, 1973). The overall diversity in a group of cultivars was assumed to be an average of $H$ obtained for each of the six Gli loci.

The statistical significance of the difference between values of $H$ obtained for two groups of cultivars was calculated using ordinary Student's test ( $\mathrm{n}=6$, corresponding to the six Gli loci). The significance of the difference of occurrence of an allele in two temporal groups of cultivars was analyzed by the $\chi^{2}$. test with one degree of freedom (Rana and Singhal, 2015).

Cluster analysis was performed as described by Ward (1963).

\section{Results}

\subsection{Genotypes of spring common wheat cultivars bred in different countries}

No signs of genetic erosion (narrowing of polymorphism) were found either at the species level (within T. aestivum) or at the country level (Metakovsky et al., 2019).

At the country level, a strong differentiation of gliadin polymorphism between countries was noticed: the group of cultivars bred in one country had its specific set of the most frequent gliadin alleles (MFGA), differing from the MFGA from other countries. Only alleles GliA1a, Gli-B1b, Gli-D1a, Gli-A2m, Gli-B2c, Gli-D2h were found to be the MFGA in two countries each (Table 1). There was almost nothing in common (i.e. there were very big genetic distances) between genotypes of cultivars bred in Australia, Canada and the former USSR (Fig. 1). More similarity was found between Mexican and Australian wheats and between cultivars from Nordic countries and the former USSR. Genotypes of cultivars bred in Mediterranean countries (Spain, Italy and France and also Spanish landraces) formed a specific sub-cluster (Fig. 1).

The wheat germplasms of each country differed also by their levels of genetic diversity, from about $H=0.61$ to 0.62 for Canada, Mexico and NC, and up to about $H=0.83$ in Spain (Table 1).

Spanish landraces and spring cultivars bred in Mediterranean countries (Spain, France, Italy) possessed a high level of genetic diversity and relatively more identified alleles as compared with other groups. For example, in the group of 18 Italian cultivars, more alleles were found as compared with 36 cultivars from Canada, and in 16 Spanish cultivars - more than in 64 cultivars from Australia (Table 1).

\subsection{Gliadin alleles in wheat cultivars bred in regions of a country}

There have been reports of polymorphism of winter wheat grown in neighbouring countries or regions of the same country (for example, Metakovsky and Branlard, 1998; Stachel et al., 2000, Roussel et al., 2005). Surprisingly, there are few analogous publications dealing with the polymorphism in spring cultivars bred in regions even of the territorially large countries. However, an analysis of wheat genetic diversity in regions of the same country may contribute much in the comprehension of relations between breeding activities and genetic diversity (Perronner et al., 2017).

In this work, a strong differentiation of gliadin polymorphism was

Table 1

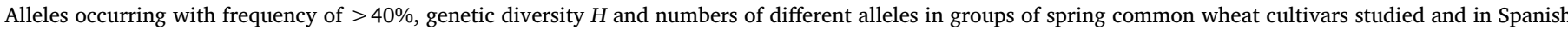
spring landraces.

\begin{tabular}{|c|c|c|c|c|c|c|c|c|c|c|}
\hline \multirow[t]{2}{*}{$\mathrm{N}^{\mathrm{a}}$} & \multirow[t]{2}{*}{ Country } & \multirow[t]{2}{*}{ Years } & \multicolumn{6}{|c|}{ The most frequent allele at the Gli locus } & \multirow[t]{2}{*}{$H$} & \multirow[t]{2}{*}{ Number of alleles ${ }^{\mathrm{b}}$} \\
\hline & & & $-\mathrm{A} 1$ & $-\mathrm{B} 1$ & $-\mathrm{D} 1$ & $-\mathrm{A} 2$ & $-\mathrm{B} 2$ & $-\mathrm{D} 2$ & & \\
\hline 64 & Australia (5 regions) & $1901-85$ & $-^{\mathrm{c}}$ & $\boldsymbol{b}$ & - & - & - & - & 0.74 & 48 \\
\hline 36 & Canada (5 regions) & $1907-88$ & $m$ & $d$ & $j$ & $m$ & $c$ & $\boldsymbol{h}$ & 0.61 & 38 \\
\hline 10 & France & $1921-87$ & af & - & $b$ & - & $o^{\mathrm{d}}$ & $\boldsymbol{h}^{\mathrm{d}}$ & 0.71 & 29 \\
\hline 18 & Italy & $1913-87$ & $a$ & - & - & - & - & - & 0.76 & 41 \\
\hline 13 & Mexico & $1962-73$ & $a$ & - & - & $f$ & $c$ & - & 0.62 & 26 \\
\hline 16 & $\mathrm{NC}^{\mathrm{e}}$ & $1921-81$ & - & $b$ & $a$ & $m$ & - & $a$ & $0.63^{\mathrm{f}}$ & 26 \\
\hline 16 & Spain (without landraces) & 1921-92 & - & - & - & - & - & - & 0.84 & 59 \\
\hline 9 & Spain landraces & & - & $o$ & - & - & - & - & 0.77 & 32 \\
\hline 117 & USSR $^{g}$ ( 5 regions) & 1923-93 & - & $e$ & $a$ & $q$ & - & - & 0.72 & 77 \\
\hline
\end{tabular}

Notes.

a Number of cultivars studied. Non-registered cultivars or cultivars having contradictory year of registration (in total, 10 cultivars of 290 studied) were included.

b Sum of alleles at six gliadin loci in a group of cultivars.

c No one allele occurred with the frequency of $>40 \%$ at this locus in a given group.

d Frequency of this allele at this locus in this group $=40 \%$.

e NC, Nordic countries: Finland (6 cultivars) + Norway (5) + Sweden (5).

${ }^{\mathrm{f}}$ For calculation of genetic diversity, five Gli loci were used (without Gli-B2).

g USSR, here: Russia (100 cultivars) + north Kazakhstan (17). 
Table 2

The MFGA and genetic diversity in groups of common wheat spring cultivars from different regions of Australia, Canada, NC and the former USSR.

\begin{tabular}{|c|c|c|c|c|c|c|c|c|c|c|c|}
\hline \multirow[t]{2}{*}{$\mathrm{N}^{\mathrm{a}}$} & \multirow[t]{2}{*}{ Country } & \multirow[t]{2}{*}{ Region $^{\mathrm{b}}$} & \multirow[t]{2}{*}{ Years } & \multicolumn{6}{|c|}{ The most frequent allele at the Gli locus ${ }^{\mathrm{c}}$} & \multirow[t]{2}{*}{$H$} & \multirow[t]{2}{*}{ Number of alleles } \\
\hline & & & & $-\mathrm{A} 1$ & $-\mathrm{B} 1$ & $-\mathrm{D} 1$ & $-\mathrm{A} 2$ & $-B 2$ & $-\mathrm{D} 2$ & & \\
\hline 9 & Australia & WA & 1929-78 & $m$ & $\boldsymbol{b}$ & $a$ & $a$ & an & $w$ & 0.55 & 18 \\
\hline 7 & Australia & QLD & $1972-81$ & $g$ & $\boldsymbol{b}$ & $\boldsymbol{b}$ & $f$ & $c$ & $q$ & 0.53 & 20 \\
\hline 8 & Australia & SA & $1952-82$ & $m$ & $b$ & $i$ & $a$ & - & $w$ & 0.67 & 26 \\
\hline 26 & Australia & NSW & $1901-83$ & - & $b$ & $f$ & $c$ & $c$ & - & 0.65 & 31 \\
\hline 13 & Australia & Victoria & $1922-85$ & $a f$ & $i$ & - & $a$ & $i$ & $i$ & 0.61 & 27 \\
\hline 12 & Canada & Sask & $1911-88$ & $m$ & $d$ & $j$ & $m$ & $c$ & $\boldsymbol{h}$ & 0.55 & 23 \\
\hline 16 & Canada & West & $1911-88$ & $m$ & $d$ & $j$ & $m$ & $c$ & $\boldsymbol{h}$ & 0.57 & 27 \\
\hline 12 & Canada & Man & $1939-86$ & $m$ & $d+e$ & $j$ & $m$ & $c$ & $\boldsymbol{h}$ & 0.41 & 17 \\
\hline 15 & Canada & East & $1939-86$ & $m$ & $\boldsymbol{d}+\boldsymbol{e}^{\mathrm{d}}$ & $j$ & $m$ & $c$ & $\boldsymbol{h}$ & 0.47 & 20 \\
\hline 5 & Canada & Quebec & $1979-86$ & $f$ & $\boldsymbol{b}+\boldsymbol{e}^{\mathrm{d}}$ & $\boldsymbol{a}^{\mathrm{d}}+\boldsymbol{b}^{\mathrm{d}}$ & $\boldsymbol{w}^{\mathrm{d}}$ & $c$ & $a$ & 0.50 & 17 \\
\hline 42 & USSR & Saratov & $1923-86$ & $f$ & $e$ & $a$ & $q$ & $s$ & $e$ & 0.51 & 39 \\
\hline 10 & USSR & South Ural & 1949-91 & - & $\boldsymbol{b}^{\mathrm{d}}$ & $a$ & $m$ & - & - & 0.72 & 30 \\
\hline 34 & USSR & Omsk & 1929-93 & $f$ & $e$ & $a$ & - & - & - & 0.75 & 47 \\
\hline 14 & USSR & East Siberia & $1947-89$ & $k$ & $b$ & $a$ & $q$ & $k$ & - & 0.58 & 28 \\
\hline 17 & USSR & NK & 1945-93 & - & $e$ & $a$ & - & $d$ & $e$ & 0.66 & 29 \\
\hline 6 & NC & Finland & 1949-81 & $m$ & $b+k$ & $a$ & $u$ & - & - & $0.49^{\mathrm{e}}$ & 18 \\
\hline 5 & NC & Norway & $1952-75$ & $c$ & $b$ & $a$ & - & $g$ & $a$ & $0.56^{\mathrm{e}}$ & 18 \\
\hline 5 & NC & Sweden & $1921-81$ & - & - & - & $m$ & - & $a$ & $0.51^{\mathrm{e}}$ & 16 \\
\hline
\end{tabular}

Notes.

a Number of cultivars in the group.

b Regions: WA: Western Australia; SA: South Australia; QLD: Queensland; NSW: New South Wales; Sask: Saskatchewan; Alb: Alberta; Man: Manitoba; Ont: Ontario;

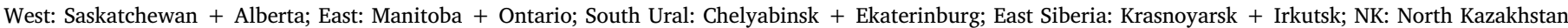
(Tselinograd + Karaganda).

c Two different alleles at the same Gli locus occurring each with the fequenciy exceeded $40 \%$ were joined by the sign "+".

d The frequency of this allele at this locus in this group $=40 \%$.

e For calculation of $\mathrm{H}$ of cultivars bred in NC, five Gli loci were used (without Gli-B2).

discovered between regions of one country analogous to that found between countries.

Each of five groups of Australian cultivars (bred in the states of Western Australia, South Australia, Queensland, New South Wales and Victoria) were characterized by their specific sets of MFGA, geographical neighbours Western and South Australia being the most similar in their frequent alleles (Table 2). The five groups of cultivars composed one cluster and did not relate to any non-Australian group of cultivars studied with the exception of Mexican wheats (Fig. 1). This result reflects the frequent interchanges of wheat cultivars between Australian states and the introduction of germplasm from CIMMYT since the 1950s (Macindoe and Walkden Brown, 1968). Inside the Australian cluster, the shortest genetic distance was between cultivars bred in New South Wales and South Australia while cultivars from

Table 3

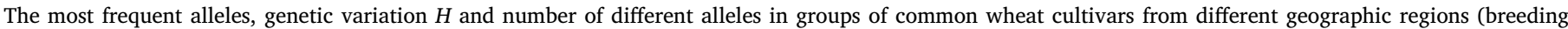
centres) during the 20th century.

\begin{tabular}{|c|c|c|c|c|c|c|c|c|c|c|c|}
\hline \multirow[t]{2}{*}{$\mathrm{N}$} & \multirow[t]{2}{*}{ Country } & \multirow[t]{2}{*}{ Region $^{\mathrm{a}}$} & \multirow[t]{2}{*}{ Years } & \multicolumn{6}{|c|}{ The most frequent allele at the Gli locus } & \multirow[t]{2}{*}{$H$} & \multirow[t]{2}{*}{ Number of alleles } \\
\hline & & & & $-\mathrm{A} 1$ & $-\mathrm{B} 1$ & -D1 & $-\mathrm{A} 2$ & $-\mathrm{B} 2$ & -D2 & & \\
\hline 8 & Australia & NSW & $1901-60$ & - & $\boldsymbol{b}$ & $f$ & $c$ & $c+a n$ & $w+t$ & 0.63 & 22 \\
\hline 8 & Australia & NSW & $1964-72$ & $g$ & $b$ & $f$ & $c$ & $c$ & $h$ & 0.61 & 24 \\
\hline 9 & Australia & NSW & $1973-83$ & $a$ & $b$ & $f$ & $c$ & $c$ & $q$ & 0.53 & 22 \\
\hline 7 & Australia & Victoria & $1922-56$ & $f+a f$ & $i$ & $a$ & $a$ & $i+a b$ & $i$ & 0.60 & 21 \\
\hline 6 & Australia & Victoria & $1962-85$ & $a f$ & $i$ & $i$ & $a$ & $i$ & $i$ & 0.50 & 17 \\
\hline 7 & Canada & West & 1911-75 & $m$ & $b+d$ & $a+j$ & $m$ & $c$ & $\boldsymbol{h}$ & 0.52 & 17 \\
\hline 9 & Canada & West & $1981-88$ & $m$ & $d$ & $j$ & $f$ & $c$ & $\boldsymbol{h}$ & 0.48 & 21 \\
\hline 7 & Canada & East & $1907-59$ & $m$ & $e$ & $a+j$ & $m$ & $w+c$ & $\boldsymbol{h}$ & 0.51 & 16 \\
\hline 8 & Canada & East & $1965-86$ & $m$ & $d$ & $j$ & $m$ & $c$ & $\boldsymbol{h}$ & 0.28 & 13 \\
\hline 6 & USSR & Omsk & $1929-40$ & - & - & $a$ & $a k$ & $o$ & $a$ & 0.64 & 22 \\
\hline 9 & USSR & Omsk & $1972-79$ & $f$ & $e$ & $a$ & $q$ & - & $e$ & 0.68 & 26 \\
\hline 8 & USSR & Omsk & $1980-88$ & $f$ & $b$ & $a$ & - & - & - & 0.70 & 30 \\
\hline 7 & USSR & Omsk & 1989-93 & - & $e$ & $a$ & $k$ & - & - & 0.64 & 24 \\
\hline 5 & USSR & Omsk & 1991-93 & $k$ & $\boldsymbol{b}^{\mathrm{b}}+\boldsymbol{e}^{\mathrm{b}}$ & $a$ & $k$ & $b$ & $a$ & 0.63 & 21 \\
\hline 9 & USSR & Saratov & 1923-31 & - & $e$ & $a$ & $q$ & - & $e$ & 0.60 & 25 \\
\hline 8 & USSR & Saratov & $1938-47$ & - & $e$ & $a$ & $q$ & - & - & 0.57 & 22 \\
\hline 8 & USSR & Saratov & $1948-62$ & $f$ & $e$ & $a$ & $q$ & $s$ & $e$ & 0.39 & 16 \\
\hline 10 & USSR & Saratov & $1963-76$ & $f$ & $e$ & $a$ & $q$ & $\boldsymbol{s}+\boldsymbol{q}^{\mathrm{b}}$ & $e$ & 0.30 & 16 \\
\hline 7 & USSR & Saratov & 1977-87 & $f$ & $e$ & $a$ & $q$ & $s$ & $e$ & 0.46 & 19 \\
\hline 4 & USSR & Saratov & $1983-87$ & $f$ & $e$ & $a$ & $q$ & $s$ & $e$ & 0.38 & 13 \\
\hline 7 & USSR & Kazakhstan & $1945-67$ & - & $e$ & $i$ & $a k$ & $d$ & - & 0.61 & 22 \\
\hline 10 & USSR & Kazakhstan & 1973-93 & - & $e$ & $a$ & $\boldsymbol{q}^{\mathrm{b}}$ & $d^{\mathrm{b}}$ & $e$ & 0.54 & 20 \\
\hline
\end{tabular}

Notes.

a Designations of regions as in footnote to Table 3.

b Frequency of this allele at this locus in this group $=40 \%$. 


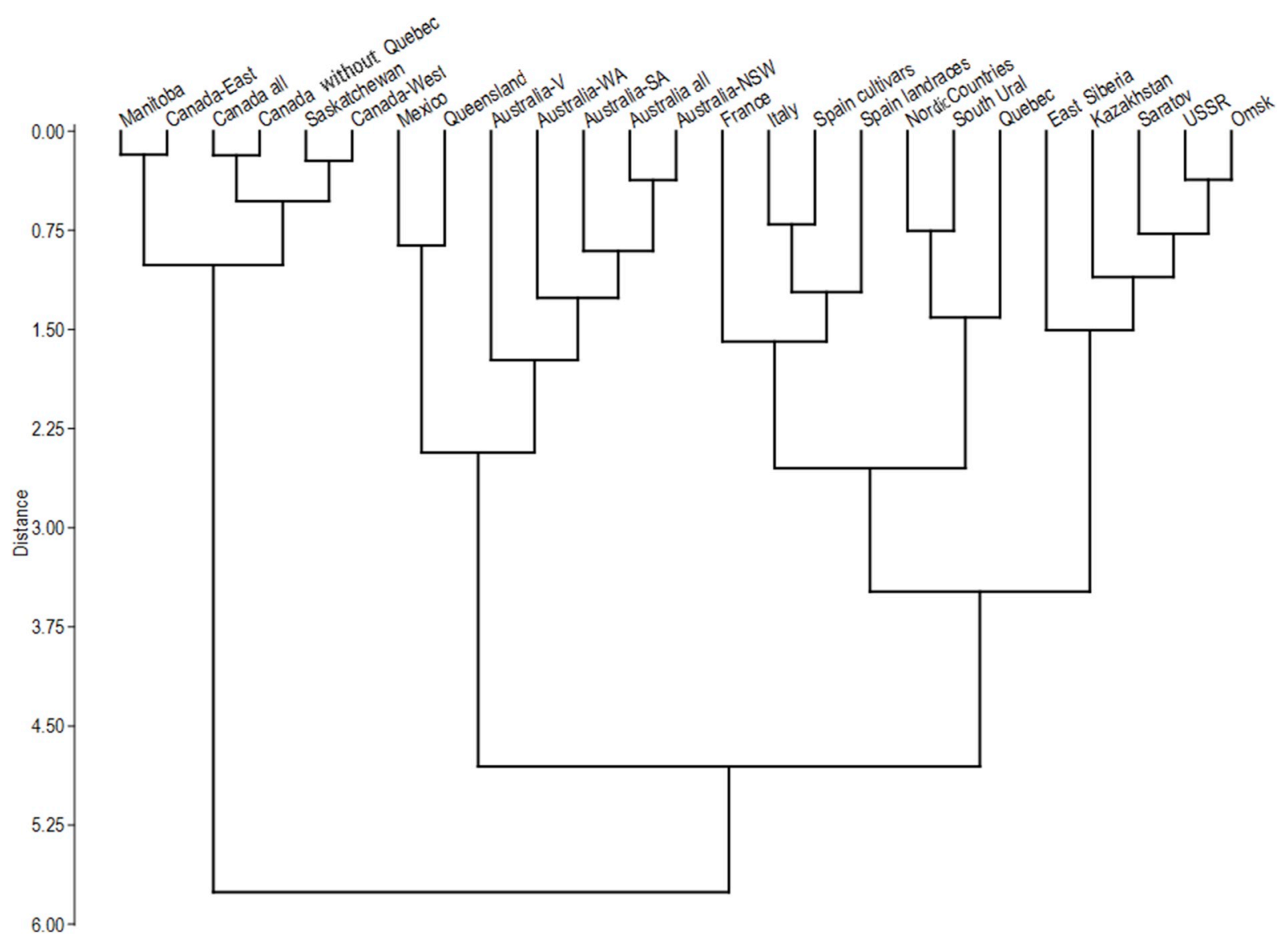

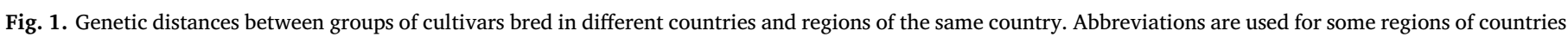

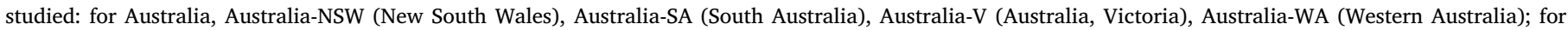

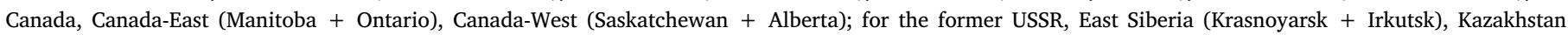

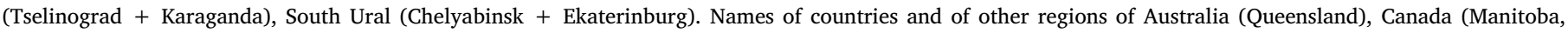
Quebec, Saskatchewan) and the former USSR (Omsk, Saratov) are indicated without abbreviation.

Queensland were more separated (Fig. 1). Two states, Queensland and Western Australia, differed from other states by a low level of genetic diversity (Table 2).

In Canada, the majority of cultivars with known Gli alleles were bred in two provinces, Manitoba and Saskatchewan, both having almost identical sets of MFGA. However, the group of cultivars from Manitoba had the least level of $H$ of all countries and regions studied, and fewer alleles as compared with those bred in Saskatchewan (Table 2). Analysis of the pedigrees of Canadian cultivars showed that, in Manitoba, 11 out of 12 cultivars had the cultivar Thatcher or its daughter Neepawa as a principal parent, while Saskatchewan's 12 cultivars had a broader set of parents, and only six of them had "Thatcher's pedigree".

Groups of Canadian cultivars studied (without Quebec) composed one cluster which had nothing in common with other groups studied (Fig. 1). In contrast, genotypes of a small group of cultivars studied from the most eastern province of Quebec differed completely from ones from other parts of Canada (Table 2, Fig. 1).

Genotypes of cultivars bred in three Nordic countries (NC) differed in their MFGA (Table 2). Differences between genotypes of spring cultivars bred in Scandinavian countries were described earlier using DNA markers (Christiansen et al., 2002).

Four regions (breeding centres) of Russia considered in this work, middle Volga region (Saratov), south Ural, west Siberia (Omsk), and east Siberia, are situated in similar geographic latitudes in the territory of Russia, from west to east, respectively, but they differ in their ecoclimatic conditions. Cultivars from the north of Kazakhstan (this country was a part of the former USSR) were included in the analysis.

A considerable differentiation of gliadin polymorphism was found between regions of the former USSR (as between states of Australia), although the similarity was observed at the Gli-B1 and Gli-D1 loci (Table 2). Cultivars from four regions composed a definite cluster; the most similar genotypes being produced in Saratov and Omsk (Fig. 1, Table 2). Cultivars bred in South Ural formed a strange sub-cluster together with cultivars of Quebec and NC (Fig. 1).

The level of genetic diversity differed greatly between cultivars from five regions, from $H=0.51$ in Saratov up to more than $H=0.70$ in the south Ural and Omsk (Table 2).

It is interesting that the genetic diversity of Australian, Canadian and the former USSR's cultivars varied more widely between groups of cultivars from regions than from whole countries (Table 2, compare with Table 1).

\subsection{Genotypes of cultivars bred in different regions during the 20th century}

Does the distribution of polymorphism between regions of a country change or maintain with the passage of time? Some minor time-based alterations in the set of the MFGA and $H$ were discovered in groups of cultivars bred in the states New South Wales and Victoria of Australia and in regions "West" and "East" of Canada (Table 3). In addition, statistically significant temporal changes in the frequency of some individual gliadin alleles were discovered.

In Australia, in the group of more recent cultivars bred in New South Wales, there was the disappearance of the local alleles Gli-D2w and Gli$D 2 t$ (for each, $\mathrm{p}<0.05$ ), and, in Victoria's cultivars, of the allele Gli$D 1 a(\mathrm{p}<0.02)$. The allele Gli-D1a also disappeared from more recent cultivars released in Canadian regions "West" $(\mathrm{p}<0.01)$ and "East" 
( $\mathrm{p}<0.05)$. In more recent cultivars of Canada "West", the allele Gli$A 2 f$, new for Canadian germplasm, appeared $(\mathrm{p}<0.02)$, whereas in cultivars of Canada "East", alleles Gli-B1d $(\mathrm{p}<0.02)$ and Gli-B2c $(\mathrm{p}<0.05)$ were propagated, while Gli-B2w disappeared $(\mathrm{p}<0.05)$. Most of these changes were also documented at the country level (Metakovsky et al., 2019). Temporal allelic changes in Canadian wheat germplasm analyzed using different types of microsatellites were described earlier in the profound works of Fu and co-workers (Fu et al., 2006; Fu and Somers, 2011).

In each of two regions of both Australia and Canada, there was a decrease, more or less prominent in each case, of the genetic diversity index $H$, the greatest drop being discovered for the region "East" of Canada (Manitoba + Ontario), from $H=0.506$ to $H=0.284$ $(\mathrm{p}<0.05)$. The same result was obtained for cultivars from the province of Manitoba only (data not shown).

In the Saratov breeding centre of the former USSR, genotypes selected from local landraces in the beginning of the 20th century were exploited in breeding for many years. This strategy maintained the same set of MFGA during several decades, resulting in the selection of several high-quality cultivars, but, as a result, the diversity index $H$ dropped ( $<<0.05$ ) to a record low level (Table 3). Each of ten cultivars studied, bred in 1963-76, carried alleles Gli-B1e and Gli-D1a, and at least seven of them - alleles Gli-A1f, Gli-A2q and Gli-D2e. Frequency of alleles Gli-B1e $(\mathrm{p}<0.01)$ and Gli-D2e $(\mathrm{p}<0.05)$ increased significantly in this group of cultivars as compared with nine cultivars bred in Saratov in 1923-31. As a result, a statistically significant $(p<0.05)$ difference (loss) of the genetic diversity was observed in Saratov's cultivars between 1923-31 and 1963-76.

An increase in genetic diversity for seven of Saratov's cultivars bred in 1977-87 was caused by the introduction of some foreign cultivars as parents. However, the last four cultivars studied (bred in 1979-87) still had a set of the MFGA typical for this breeding centre and a very low level of genetic diversity. The average index of relationship for pedigrees of cultivars bred in Saratov during the 20th century was as high as half-siblings and higher (Dobrotvorskaya et al., 2004).

In Omsk, spring cultivars from Saratov and other sources were widely used in breeding programs in the second part of the 20th century. About a half of Omsk's cultivars bred in the period from 1972 to 1993 involved winter cultivars (Bezostaya-1, Mironovskaya-808, Kavkaz) as a principal parent, permitting the continued presence of a comparatively high frequency of genetic diversity of cultivars bred in this region. The frequency of one allele, Saratov's Gli-A2q, might have increased $(\mathrm{p}<0.1)$ during the period studied.

The first known cultivar bred in North Kazakhstan was Akmolinka-1 (1945) which did not inherit any Gli allele from the Canadian cultivar Marquis (Metakovsky, 2015) which was claimed to be one of its two parents. Alterations in the set of the MFGA and decreases of the level of genetic diversity (Table 3) were caused by the transition, in breeding programs, from local accessions and Akmolinka-1 to the wide use of Saratov's cultivars. As a result, genotypes of Kazakh cuitivars became similar to those of Saratov, retaining only one allele (Gli-B2d) from Akmolinka-1. The frequency of Saratov's allele Gli-D1a increased ( $\mathrm{p}<0.01$ ), and of the local allele Gli-A2ak dropped ( $<<0.01)$ during the period studied.

The cluster analysis convincingly showed that a strong differentiation of gliadin polymorphism between countries and regions was reproduced with time, with minor changes, during the 20th century (Fig. 2). For example, genotypes of cultivars bred in Australian states, Victoria and New South Wales, composed two well-separated subclusters. Wheat genotypes from two Canadian regions studied also formed two sub-clusters, but temporal rather than spatial. Some of USSR's early cultivars (Omsk, 1929-40 and Kazakhstan, 1945-67) formed a sub-cluster strongly separated from that composed by more recent cultivars bred in the same regions with the involvement of Saratov germplasm (Omsk, 1972-79 and Kazakhstan, 1973-93) (Fig. 2).

We suggest that creditable results of analysis of wheat polymorphism and its temporal changes may be obtained only when regions (provinces) of a big country would be considered individually. In two regions ("East" of Canada and Saratov of the former USSR), an erosion of genetic diversity $(H)$ with time was confirmed statistically.

\section{Discussion}

In this work, alleles at the Gli loci were used to trace differences between wheat genotypes bred and grown in several countries situated in four continents and in regions within Australia, Canada and the former USSR. Analysis of the MFGA and $H$ at a regional scale permitted the exploration of inferences at a country level. We assume that some decrease of genetic diversity did exist in groups of cultivars bred in regions of Australia, Canada, and the former USSR (Table 3). Moreover, in the region "East" of Canada (Manitoba + Ontario) and in the Saratov region of the former USSR, a loss of genetic diversity was confirmed statistically. However, due to regional differences of genotypes (Tables 2 and 3; Figs. 1 and 2), overall genetic diversity of wheat calculated at the country level did not decrease and even increased with time in some cases (Metakovsky et al., 2019).

It was found that the frequency of occurrence of the alleles Gli-B2c and Gli-B1d significantly increased with time in the "East" region of Canada. Finally, each of 19 Canadian ("West" + "East") cultivars studied bred in 1965-88 carried the allele Gli-B2c, and 14 of them - the Gli-B1d allele (Table S1 in Metakovsky et al., 2018). The frequencies of the Gli-B2c and Gli-B1d increased with time in Australian and in Mexican germplasm (Metakovsky et al., 2019). The presence of each of these alleles and also of the Gli-B1b in wheat genotypes correlated with greater dough strength (reviewed in Metakovsky, 2015). Therefore, frequencies of these alleles in wheat germplasm might increase due to indirect breeders' selection for end-use (dough) wheat quality for breadmaking.

We have discovered that some Gli alleles frequent in one region scarcely occurred in unrelated cultivars from other countries or regions (Tables 1 and 2). Obviously, world-wide polymorphism of spring common wheat is differentiated and strongly structured between countries and also among geographical regions of the same country.

Cultivars studied differed between countries not only in their gliadin genotypes. In analysis of the distribution of some botanical varieties of common wheat (data from wheatpedigree. net) between cultivars bred in different regions, it was discovered that their distribution, analogously to gliadin alleles, differed significantly between countries. For example, varieties albidum, graecum, and lutescens occurred with the frequency of $40.6 \%, 28.1 \%$, and $0.0 \%$ in Australian cultivars, of $0.0 \%, 2.8 \%$, and $66.7 \%$ in Canadian ones, and of $40.5 \%$, $0.0 \%$, and $33.3 \%$ in Saratov. Moreover, variety alborubrum occurred almost exclusively in cultivars bred in the south-eastern regions of Australia, South Australia (37.5\% of all cultivars of this state), New South Wales (15.4\%), and Victoria (53.8\%). Only three non-Australian cultivars studied were alborubrum (overall frequency $0.01 \%$ ), one of them, Canaleja from Spain, being a descendant of the alborubrum parent from Australia.

Many wheat genotypes from around the world are commonly employed in the breeding programs of each breeding centre. For example, to breed 340 spring USSR cultivars, 255 local and alien genotypes from Europe, America, Asia and Africa were used (Dobrotvorskaya et al., 2004). However, as we have established, only a few genotypes used in breeding programs contribute their Gli alleles to newly-released cultivars of a particular breeding centre. What is the reason of the observed domination of an allele or their combination in a group of cultivars bred in a given country or region? Who performs the selection?

Analysis of morphological characters, enzymes, grain storage proteins (Nevo et al., 1995) and DNA molecular markers (Pagnotta et al., 1995) showed that self-pollinated species of wild plants demonstrate substantial differences in the frequency of alleles and genotypes between their populations (Nevo, 1994; Worland et al., 1994). There 


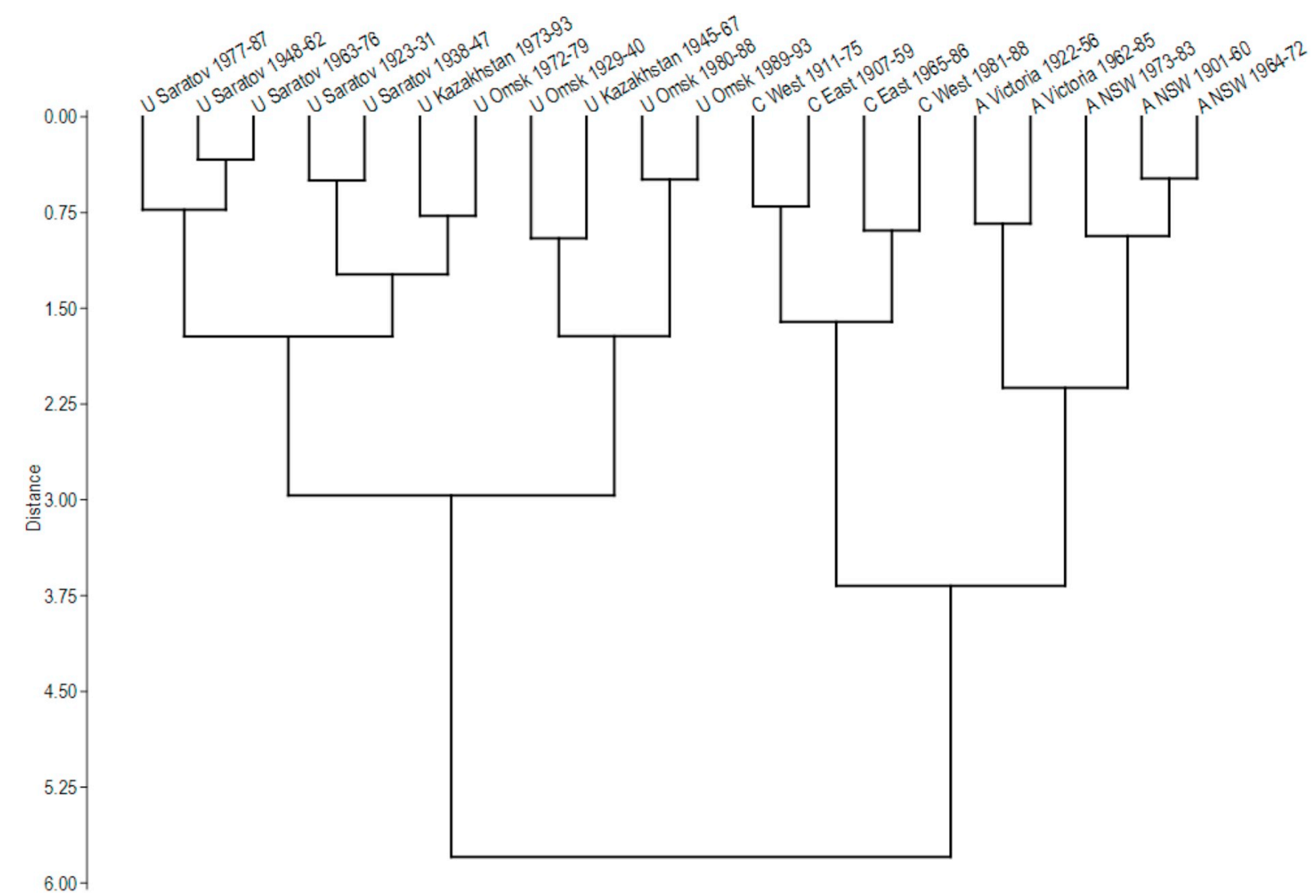

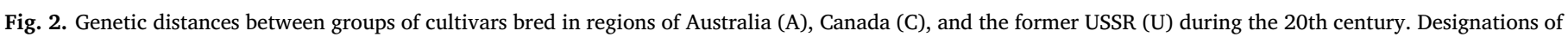
regions as in Table 2.

seems to be a logical analogy between a group of cultivars (genotypes) bred in a given region and a group of plants (genotypes) composing a population of wild wheats: in both cases, larger genetic distances were observed among regions (populations) and less inside each region (population) (Figs. 1 and 2).

There are weighty arguments that environmental factors (climate, peculiarities of soil, plant diseases) might cause an observed difference between genotypes which compose local wild wheat populations (reviewed in Nevo, 1994). It was documented that the presence of some gliadin alleles in genotypes of French cultivars correlated significantly with the time of flowering and the cold resistance of plants (Metakovsky and Branlard, 1998). There is a strong difference between gliadin genotypes of spring and winter wheats (Metakovsky et al., 2018). Considerable temporal changes in the assemblage of genotypes were documented in studies of the experimental populations of winter (Kolyuchii and Sozinov, 2000; Raquin et al., 2008) and spring (Koval and Metakovsky, 1985) common wheats, and they were interpreted to be caused by natural selection in a particular environment. Obviously, selection for end-use wheat quality could not cause the observed worldwide structuring of wheat polymorphism.

We suggest that differentiation of polymorphism of common wheats studied among countries and regions may have adaptive significance, as is proved for wild wheats. Natural selection (caused by eco-climatic conditions) may act in different ways in different regions, limiting the level of genetic diversity of wheat grown in this region: it is known that only a short list of genotypes successful for a given area or region is available (Prasad et al., 2000). It was shown that modern breeding has reduced the genetic diversity of Canadian wheats (Fu and Somers, 2009). We suggest, however, that each newly-bred cultivar is always the fruit of the joint efforts of a breeder pursuing his own aims and of natural selection acting in a given region in all stages of the breeding process, from producing crosses to propagation of the finally selected genotype.

Analysis of wheat polymorphism through the application of different molecular markers (microsatellites, SSR, DNA polymorphism, RFLP, retrotransposons) for different segments of common wheat germplasm permits the conclusion that there are no convincing proofs of genetic erosion in wheat (reviewed in Van de Wouw et al., 2010). Our data provide new insights for discussions (Porceddu et al., 1988; Thormann and Engels, 2015) about possible genetic erosion of wheat germplasm during the 20th century.

A regionally-specific natural selection may cause temporal "specialization" of polymorphism for each region increasing differences between genotypes bred in each of different regions. As a result, the index $H$ calculated for a country composed of several regions might show an elevated genetic diversity of wheat at a country level and, certainly, at the species level.

On the other hand, the necessity of plants to adapt to the particular eco-climatic growth conditions of the region may determine and limit the number of genotypes successful in these conditions. Our results did indicate a temporal genetic erosion, but in a few cases and at the regional level only. We suggest that there may be a considerable contribution of natural selection in the erosion observed at the regional level.

An extremely high level of diversity of common wheat germplasm of the 20th century was, is, and will be maintained over time due to diversity, on a world-wide scale, of natural selection in different ecoclimatic environments of wheat cultivation in spite of the selection, in different countries, for similar wheat characters, such as improved enduse (dough) quality. Successful genotypes may perhaps contribute to a narrowing polymorphism at the regional level. However, it is difficult to imagine a specific/single wheat genotype which would fit any combination of eco-climatic conditions of growing at world-wheatgermplasm and at country levels. An erosion of genetic diversity of $T$. 
aestivum at a species level would be unavoidable only if eco-climatic conditions became identical everywhere that wheat is grown.

\section{Conclusion}

In this work, it was proved that polymorphism of spring common wheat was extremely high and highly structured between countries and their regions studied. This differentiation of polymorphism might have adaptive significance, as has proved for wild wheats, while selection for end-use wheat quality scarcely influences the genetic polymorphism of wheat. Therefore, a very high level of diversity of common wheat germplasm of the 20th century was, is, and will be maintained over time due to diversity, on a world-wide scale, of natural selection in different eco-climatic environments of wheat cultivation and, in addition, due to distinct breeders' aims in their breeding programs. An erosion of genetic diversity of $T$. aestivum would be unavoidable only if eco-climatic conditions became identical everywhere that wheat is grown.

\section{Conflicts of interest}

The authors declare that they have no conflicts of interest.

\section{Appendix A. Supplementary data}

Supplementary data to this article can be found online at https:// doi.org/10.1016/j.jcs.2019.04.015.

\section{References}

Branlard, G., Dardevet, M., Amiour, N., Igrejas, G., 2003. Allelic diversity of HMW and LMW glutenin subunits and omega-gliadins in French bread wheat (Triticum aestivum L.). Genet. Resour. Crop Evol. 50, 669-679.

Brown, A.H.D., Hodgkin, T., 2015. Indicators of genetic diversity, genetic erosion, and genetic vulnerability for plant genetic resources. In: Sustainable Development and Biodiversity (V7), Genetic Diversity and Erosion in Plants, pp. 25-53.

Christiansen, M.J., Andersen, S.B., Ortiz, R., 2002. Diversity changes in an intensively bred wheat germplasm during the 20th century. Mol. Breed. 9, 1-11.

Dobrotvorskaya, T.V., Martynov, S.P., Pukhalskyi, V.A., 2004. Trends in genetic diversity change of spring bread eheat cultivars released in Russia in 1929-2003. Russ. J. Genet. 40, 1545-1557.

Fu, Y.B., Somers, D.J., 2009. Genome-wide reduction of genetic diversity in wheat breeding. Crop Sci. 49, 161-168.

Fu, Y.B., Somers, D.J., 2011. Allelic changes in bread wheat cultivars were associated with long-term wheat trait improvements. Euphytica 179, 209-225.

Fu, Y.B., Peterson, G.W., Yu, J.K., Gao, L., Jia, J., Richards, K.W., 2006. Impact of plant breeding on genetic diversity of the Canadian hard red spring wheat germplasm as revealed by EST-derived SSR markers. Theor. Appl. Genet. 112, 1239-1247.

Kolyichii, V.T., Sozinov, A.A., 2000. Influence of natural selection on the frequency of gliadin-coding loci, and their association in an artificially produced hybrid population of winter wheat. Cytol. Genet. 34, 32-38.

Koval, S.F., Metakovsky, E.V., 1985. Adaptive value of some quantitative and qualitative characters in model hybrid population of T. aestivum. Agricul. Biol. (Moscow) 11, 48-52 (in Russian).

Macindoe, S.L., Walkden Brown, C., 1968. Wheat breeding and varieties in Australia. In:
Science Bulletin N76, third ed. New South Wales Department of Agriculture, Sydney, Australia.

Metakovsky, E.V., 2015. Wheat Storage Proteins: Genes, Inheritance, Variability, Mutations, Phylogeny, Seed Production, Flour Quality. Lambert Acad. Pabl., Saarbrucken, Deutschland, pp. 330 (in Russian, English summary).

Metakovsky, E.V., Branlard, G., 1998. Genetic diversity of French common wheat germplasm studied using gliadin alleles. Theor. Appl. Genet. 96, 209-218.

Metakovsky, E.V., Melnik, V.A., Rodriguez-Quijano, M., Upelniek, V.P., Carrillo, J.M., 2018. A catalogue of gliain alleles: polymorphism of 20th-century common wheat germplasm. Crop J. 6 (6), 629-641. https://doi.org/10.1016/j.cj.2018.02.003.

Metakovsky, E.V., Melnik, V.A., Pascual, L., Wrigley, C.W., 2019. Gliadin genotypes worldwide for spring wheats (Triticum aestivum L.) 1. Genetic diversity and grainquality gliadin alleles during the 20th century. J. Cereal Sci. 87, 172-177.

Nei, M., 1973. Analysis of gene diversity in subdivided populations. Proc. Nat. Acad. Sci. U.S.A. 70, 3321-3323.

Nevo, E., 1994. Evolutionary significance of genetic diversity in nature: environmental stress, pattern and theory. In: Markert, C.L., Scandalios, J.G., Lim, H.A., Serov, O.L. (Eds.), Isozymes. Organization and Roles in Evolution, Genetics and Physiology, Proc. 7th Internat. Congress on Isozymes (1992, Novosibirsk, Russia). World Scientific, New Jersey, pp. 267-296.

Nevo, E., Pagnotta, M.A., Beiles, A., Porceddu, E., 1995. Wheat storage proteins: glutenin DNA diversity in wild emmer wheat, Triticum dicoccoides, in Israel and Turkey. 3. Environmental correlates and allozyme assiciations. Theor. Appl. Genet. 91, $415-420$.

Pagnotta, M.A., Nevo, E., Beiles, A., Porceddu, E., 1995. Wheat storage proteins: glutenin diversity in wild emmer, Triticum dicoccoides, in Israel and Turkey. 2. DNA diversity detected by PCR. Theor. Appl. Genet. 91, 409-414.

Perronner, R., Makowski, D., Goffaux, R., Montalent, P., Goldringer, I., 2017. Temporal evolution of varietal, spatial and genetic diversityof bread wheat between 1980 and 2006 strongly depends upon agricultural regions in France. Agric. Ecosyst. Environ. $236,12-20$.

Porceddu, E., Ceoloi, C., Lafiandra, D., Tanzarella, O.A., Scarascia Munozza, G.T., 1988. Geneic resources and plant breeding: problems and pospects. In: Miller, T.E., Koebner, R.M.D. (Eds.), Proc. 7th Internat. Wheat Genetics Symposium (v.1). IPSR, Cambridge, UK, pp. 7-22.

Prasad, M., Varshney, R.K., Roy, J.K., Balyan, H.S., Gupta, P.K., 2000. The use of microsatellites for detecting DNA polymorphism, genotype identification and genetic diversity in wheat. Theor. Appl. Genet. 100, 584-592.

Rana, R., Singhal, R., 2015. Chi-aquare test and its application in hypothesis testing. J. Pract. Cardiovasc. Sci. 1, 69-71.

Raquin, A.L., Depaulis, F., Lambert, A., Galic, N., Brabant, P., Goldringer, I., 2008. Experimental estimation of mutation rates in a wheat population with a gene genealogy approach. Genetics 179, 2195-2211.

Ribeiro, M., Carvalho, C., Carnide, V., Guedes-Pinto, H., Igrejas, G., 2011. Towards allelic diversity in the storage proteins of old and currently growing tetraploid and hexaploid wheats in Portugal. Genet. Resour. Crop Evol. 58, 1051-1073.

Roussel, V., Leisova, L., Exbrayat, F., Stehno, Z., Balfourier, F., 2005. SSR allelic diversity changes in 480 European bread wheat varieties released from 1840 to 2000 . Theor. Appl. Genet. 111, 162-170.

Stachel, M., Lelley, T., Grausgruber, H., Vollmann, J., 2000. Application of microsatellites in wheat (Triticum aestivum L.) for stadying genetic differentiation caused by selection for adaptation and use. Theor. Appl. Genet. 100, 242-248.

Thormann, I., Engels, J.M.M., 2015. Genetic diversity and erosion - a global perspective. Genetic Diversity and Erosion in Plants, vol 7. Sustainable development and biodiversity, pp. 263-298.

Van de Wouw, M., van Hintum, T., Kik, C., van Treuren, R., Visser, B., 2010. Genetic diversity trends in twentieth century crop cultivars: a meta analysis. Theor. Appl. Genet. 120, 1241-1252.

Ward, J.H., 1963. Hierarchial grouping to optinize an objective function. J. Am. Stat. Assoc. 58, 236-244.

Worland, A.J., Appendino, M.L., Sayers, E.J., 1994. The distribution, in European winter wheats, of genes that influence ecoclimatic adaptability whilst determining photoperiodic insensitivity and plant hight. Euphytica 80, 219-228. 